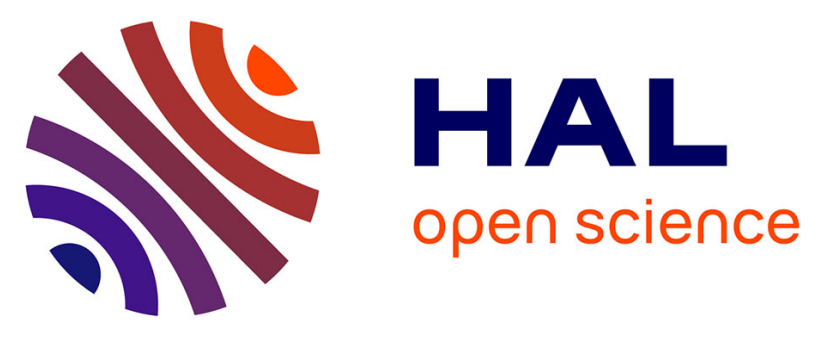

\title{
Silyl-Substituted Planar Chiral Phosphoric Acids with Ferrocene-bridged Paracyclophane Frameworks: Synthesis, Characterization, and Uses in Enantioselective aza-Friedel-Crafts Reactions
}

Jérémy Stemper, Kevin Isaac, Nayan Ghosh, Hortense Lauwick, Gaëtan Le duc, Pascal Retailleau, Arnaud Voituriez, Jean-François Betzer, Angela Marinetti

\section{- To cite this version:}

Jérémy Stemper, Kevin Isaac, Nayan Ghosh, Hortense Lauwick, Gaëtan Le duc, et al.. SilylSubstituted Planar Chiral Phosphoric Acids with Ferrocene-bridged Paracyclophane Frameworks: Synthesis, Characterization, and Uses in Enantioselective aza-Friedel-Crafts Reactions. Advanced Synthesis and Catalysis, 2017, 359 (3), pp.519-526. 10.1002/adsc.201600920 . hal-02152293

\author{
HAL Id: hal-02152293 \\ https://hal.science/hal-02152293
}

Submitted on 11 Jun 2019

HAL is a multi-disciplinary open access archive for the deposit and dissemination of scientific research documents, whether they are published or not. The documents may come from teaching and research institutions in France or abroad, or from public or private research centers.
L'archive ouverte pluridisciplinaire HAL, est destinée au dépôt et à la diffusion de documents scientifiques de niveau recherche, publiés ou non, émanant des établissements d'enseignement et de recherche français ou étrangers, des laboratoires publics ou privés. 


\title{
Silyl-Substituted Planar Chiral Phosphoric Acids with Ferrocene-bridged Paracyclophane Frameworks: Synthesis, Characterization, and Uses in Enantioselective aza-Friedel-Crafts Reactions
}

\author{
Jérémy Stemper, ${ }^{a}$ Kévin Isaac, ${ }^{a}$ Nayan Ghosh, ${ }^{a}$ Hortense Lauwick, ${ }^{a}$ \\ Gaëtan Le Duc, ${ }^{a}$ Pascal Retailleau, ${ }^{a}$ Arnaud Voituriez, ${ }^{a}$ Jean-François Betzer, ${ }^{a}$ ** \\ and Angela Marinetti ${ }^{\mathrm{a}, *}$ \\ a Institut de Chimie des Substances Naturelles, CNRS UPR 2301, Université Paris-Sud, Université Paris-Saclay, 1 av. de la \\ Terrasse, 91198 Gif-sur-Yvette, France \\ Phone: +33169823116 \\ Phone: +33169823036 \\ E-mail: jean-françois.betzer@cnrs.fr angela.marinetti@cnrs.fr
}

Received: August 19, 2016; Published online: $\mathbf{\square} \mathbf{\square}$, 0000

Supporting information for this article is available on the WWW under http://dx.doi.org/10.1002/adsc.201600920

\begin{abstract}
This manuscript reports on a suitable method for the synthesis of paracyclophane type, ferrocene-bridged chiral phosphoric acids, which bear silyl-substituents on their paracyclophane frameworks. These acids have been obtained easily in enantiomerically pure form, by taking advantage of (S)-(1-phenyl-2-cyanoethyl)phosphorodiamidite as a phosphorylating agent. They have been used then as catalysts for aza-Friedel-Crafts reactions between indoles and imines, giving high catalytic activity and up to $98 \%$ enantiomeric excess.
\end{abstract}

Keywords: asymmetric catalysis; phosphoric acid; planar chirality; paracyclophane; aza-Friedel-Crafts reactions

Since the late 1990s, the extensive research effort on asymmetric organocatalysis led to the development of an essential toolbox for a wide range of enantioselective organic transformations. ${ }^{[1]}$ In this area, chiral Brønsted acid catalysis represents a substantial contribution since numerous organic reactions are promoted by hydrogen bonding activation and/or Brønsted acid activation via contact ion pairs. ${ }^{[2]}$ Since the pioneering work of Akiyama ${ }^{[3]}$ and Terada ${ }^{[4]}$ in 2004, on BINOL-derived phosphoric acids, Chiral Phosphoric Acids (CPA) have afforded a rapidly growing sub-field of Brønsted acid catalysis.

This success might be ascribed to the nature of the PA function, where the two oxygen atoms of a chiral diol can be directly attached to the phosphorus atom, providing an efficient chiral environment. The PA function also allows the simultaneous presence of a phosphoryl function (Brønsted basic site) and a hydroxyl moiety (Brønsted acidic site), thus operating as a bifunctional catalyst. After the first development of BINOL-derived PA ${ }^{[5]}$ the efficiency of PA derived from other axially chiral diols like VAPOL, ${ }^{[6]}$ VANOL ${ }^{[7]}$ bisphenol, ${ }^{[8]}$ SPINOL $^{[9]}$ and others ${ }^{[10]}$ has been investigated. Thus, the current design of CPAs is focused mainly on axial chirality and very few examples of CPA with central ${ }^{[1]]}$ and planar ${ }^{[12]}$ chirality are reported in the literature. In this context, we have designed phosphoric acids with a planar chiral paracyclophane backbone tethered by either a $1,1^{\prime}$-ferrocenediyl ${ }^{[13]}$ or a 1,8 -biphenylenediy ${ }^{[14]}$ unit (Figure 1 ) as potentially useful unprecedented CPAs.

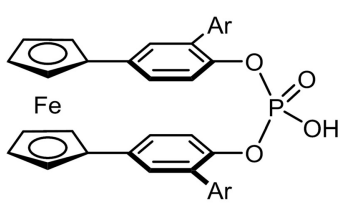

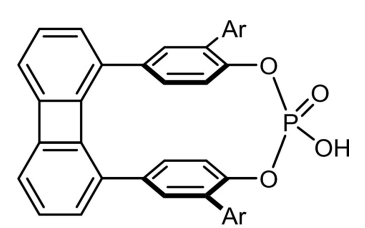

II
Figure 1. Previously reported phosphoric acids with planar chiral paracyclophane structures.

Following our initial studies in this field, in this manuscript we report on the synthesis of ferrocenebridged phosphoric acids, which bear silyl-substituents on their paracyclophane frameworks. We also describe 
the use of these new phosphoric acids as catalysts for aza-Friedel-Crafts reactions.

In our previous work on ferrocene-bridged, paracyclophane type phosphoric acids, planar chirality was generated through the presence of aryl substituents on both arylidene rings, in ortho position with respect to the phosphorus functions. These aryl groups were introduced from their bromide precursors by Suzuki cross-coupling reactions. With the aim to expand this family of phosphoric acids and their potential uses in asymmetric organocatalysis, we have envisioned the introduction of substituents with different steric and geometrical features with respect to aryl groups. Thus, we turned our attention to silyl substituents which can generate high steric hindrance near to the phosphorus function, with a peculiar spherical arrangement (Figure 2). These substituents have been largely used to modulate and optimize the catalytic properties of BINOL derived phosphoric acids. Notably, silyl-substituted phosphoric acids have been introduced in 2006 by MacMillan to catalyze enantioselective reductive amination reactions. ${ }^{[15]}$ Also, BINOL-derived phosphoric acids with triphenylsilyl substituents have been reported to be excellent catalysts for the FriedelCrafts reactions of indole with imines. ${ }^{[16]}$

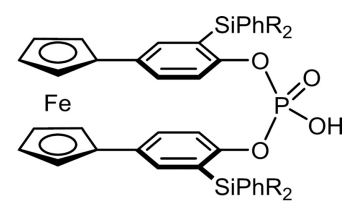

III

Figure 2. Targeted silyl-substituted phosphoric acids.
Our approach to the targeted silylated phosphoric acids involves a retro-[1,3]-Brook rearrangement as the key step (Scheme 1). The synthesis starts from the previously described 1,1'-bis-[4-(methoxy-methyloxy) phenyl]ferrocene $\mathbf{3}$ which is obtained in $80 \%$ yield from the commercially or readily available $1,1^{\prime}$ diiodoferrocene, 1, and 4-(methoxy-methyloxy)phenylboronic acid, 2, by Suzuki cross-coupling. ${ }^{[13 a]}$

Taking advantage of the ortho-directing effect of the MOM group, compound $\mathbf{3}$ has been converted into the corresponding bis-iodinated derivative through a metalation-iodination sequence. Compared to the procedure used for the BINOL derivatives, where an excess of the metalating agent is required, ${ }^{[17]}$ the metalation must be carried out here with only 2 equiv. of $n$-BuLi to avoid metalation of the ferrocenyl moiety. Also, to avoid side-reactions of the ferrocenyl moiety, the use of 1,2-diiodoethane is preferred to iodine as electrophilic iodination agent. ${ }^{[18]}$ After removal of the MOM groups in standard acidic conditions, the ferrocenyl bisphenol 4 is obtained in $85 \%$ overall yield, over two steps.

The silyl groups are introduced at this stage on the phenol moieties. Two silylated groups have been considered: the triphenylsilyl (TPS) and the bulky tertbutyldiphenylsilyl (TBDPS) groups. Treatment of the ferrocenyl bisphenol 4 with triphenylsilyl chloride or tert-butyldiphenylsilylchloride in the presence of imidazole as the base, afforded the bis-silyl ethers $\mathbf{5}$ a and $\mathbf{5 b}$, respectively, in excellent yields. Migration of the silyl groups onto the aromatic rings was performed via a retro-[1,3]-Brook rearrangement, ${ }^{[19]}$ by treatment of compounds 5 with 3.2 equivalents of $t$-BuLi, in order to prevent the undesired metalation of the ferrocenyl moiety. ${ }^{[20]}$ The intramolecular $O$-silyl to $C$ -
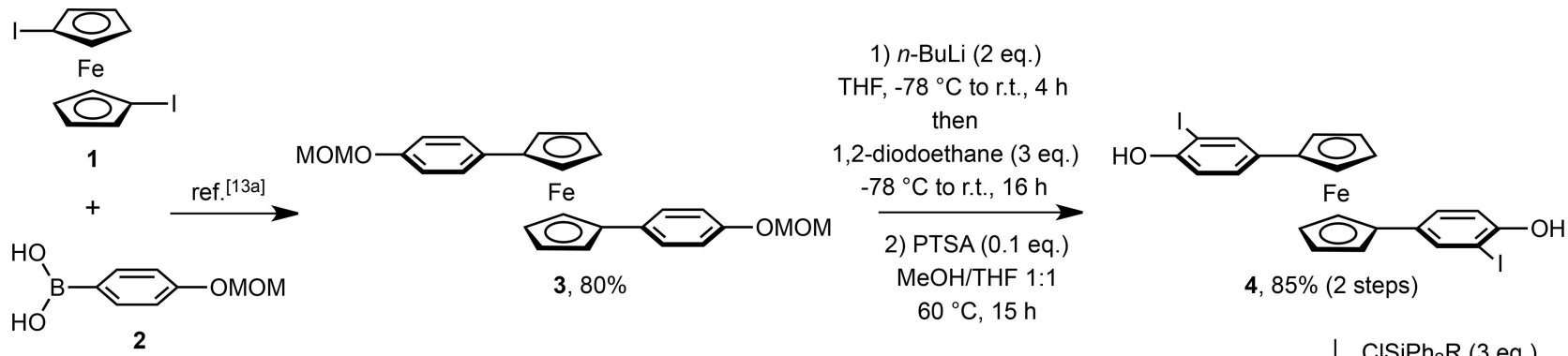

$60{ }^{\circ} \mathrm{C}, 15 \mathrm{~h}$
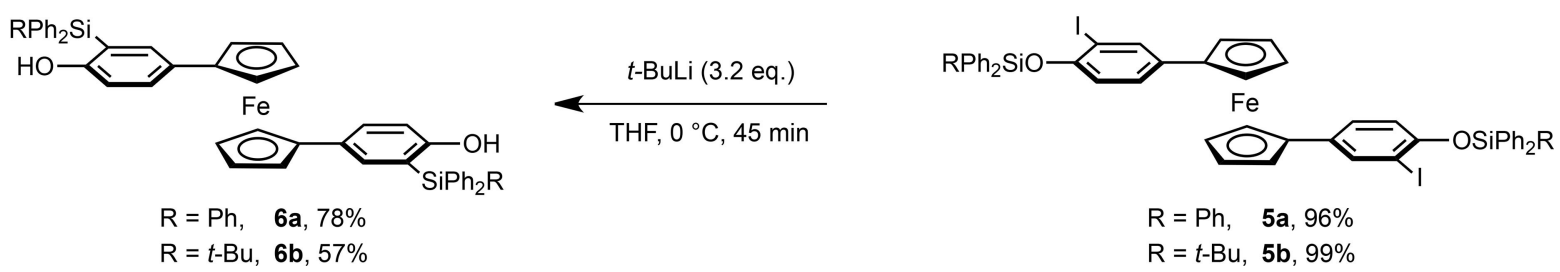

Scheme 1. Synthesis of the silylated bisphenols $6 \mathbf{a}$ and $\mathbf{6 b}$. 
silyl rearrangement afforded the desired silylated bisphenols $\mathbf{6 a}$ and $\mathbf{6 b}$ in $78 \%$ and $57 \%$ yields, respectively. The overall yields for $\mathbf{6 a}$ and $\mathbf{6 b}$, over four steps from 3 , are of $64 \%$ and $48 \%$ respectively.

With these precursors of the targeted silyl-substituted paracyclophanes in hand, the challenging phosphorylation/macrocyclization step has been investigated. The reaction was first attempted on the triphenylsilyl derivative $\mathbf{6 a}$ with the commercially available 'Phos reagent' (2-cyanoethyl $N, N, N^{\prime}, N^{\prime}$-tetraisopropylphosphorodiamidite), 7 (Scheme 2). ${ }^{[21]}$
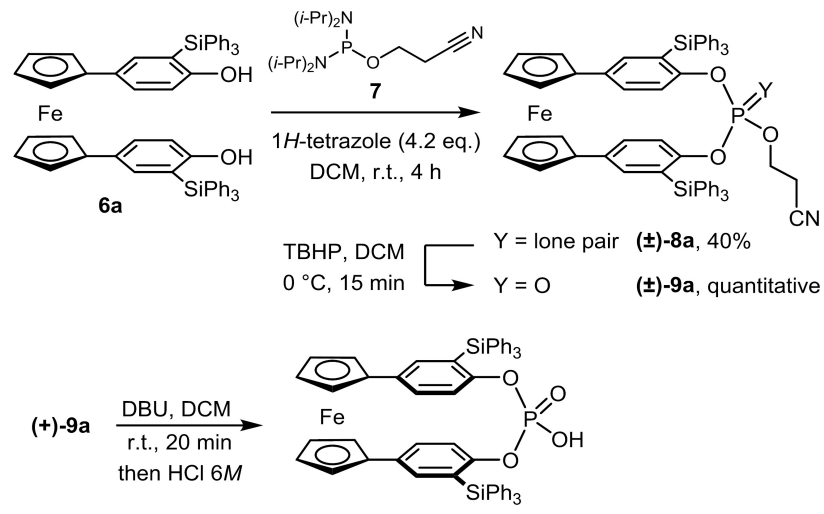

(+)-10a, quantitative

Scheme 2. Synthesis of the chiral phosphoric acid (+)-10a using the Phos reagent 7. Resolution of 9a has been performed by semi-preparative chiral HPLC (CHIRALPAK $^{\circledR}$ ID column, THF/heptane 17:83).

The phosphorylation reaction was carried out under previously optimized conditions ${ }^{[13 a]}$ (excess of $1 \mathrm{H}$-tetrazole at r.t. for 4 hours) to provide the desired paracyclophane $( \pm)-8 \mathbf{a}$ in $40 \%$ isolated yield, after purification by column chromatography on silica gel. The isomeric meso paracyclophane, in which the silyl groups are located on the same side of the macrocyclic structure, could not be isolated nor unambiguously evidenced. Compound 8a has been oxidized with TBHP to afford the corresponding phosphate $( \pm)-\mathbf{9 a}$. Enantiomeric resolution of the racemic mixture of phosphate $( \pm)-9$ a has been performed on a semipreparative scale $(100 \mathrm{mg})$ by chiral HPLC on a CHIRALPAK ${ }^{\circledR}$ ID column.

The cyanoethyl chain of phosphate $(+)-9 \mathbf{a}$ has been removed under basic conditions (DBU) to provide the desired planar chiral phosphoric acid $(+) \mathbf{- 1 0} \mathbf{a}$ in quantitative yield, after treatment with hydrochloric acid. The molecular structure of phosphoric acid (+)-10a has been assigned by a single-crystal X-ray diffraction study performed on its calcium salt $[(+)-\mathbf{1 0 a}]_{2} \mathrm{Ca}$ (Figure 3$) .{ }^{[22]}$ This salt was isolated when the DBU phosphate, initially obtained by removal of the cyanoethyl chain of $(+)-\mathbf{9 a}$, was passed through a silica gel column and eluted with methanol. ${ }^{[20 \mathrm{~b}, 23]}$ The X-ray data allowed us to assign the absolute configuration $\left(R_{\mathrm{P}}\right)$ to $(+) \mathbf{- 1 0} \mathbf{a}$.

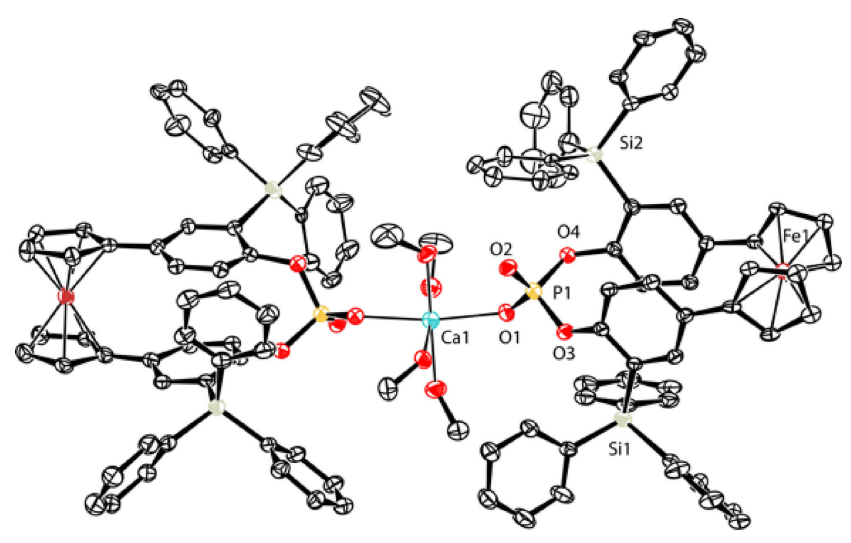

Figure 3. ORTEP drawing of $[(+)-\mathbf{1 0} \mathbf{a}]_{2} \mathrm{Ca}$.

In the synthesis of enantiopure $10 \mathrm{a}$, the chiral HPLC separation of the racemic intermediate phosphate 9, shown in Scheme 2, might represent a limiting step. Thus, in order to prepare silylated planar chiral phosphoric acids in larger amounts on a laboratory scale, we envisioned to take advantage of (S)-11, a chiral synthetic equivalent of 2-cyanoethyl phosphorodiamidite as phosphorylating agent. ${ }^{[2]}$ This reagent should allow to access enantiomerically pure phosphates by separation of the corresponding mixture of diastereomers (Scheme 3).

The bisphenols $\mathbf{6 a}$ and $\mathbf{6 b}$ have been reacted with the chiral phosphorodiamidite $(S)-\mathbf{1 1}$ in the presence of an excess of $1 H$-tetrazole at $40^{\circ} \mathrm{C}$ for 3 hours. The macrocyclic phosphites have been obtained as $6: 4$ mixtures of diastereoisomers $12 \mathbf{a} / \mathbf{1 2} \mathbf{a}^{\prime}$ and $\mathbf{1 2} \mathbf{b} / \mathbf{1 2} \mathbf{b}^{\prime}$. Yields are in the same range (36-38\%) as obtained with the achiral and less hindered phosphorylating agent 7. The non-separable mixtures of phosphites $\mathbf{1 2}$ were oxidized into the corresponding phosphates $\mathbf{1 3}$, by treatment with TBHP. At this stage, the diastereomeric phosphates $13 \mathbf{a}, \mathbf{a}^{\prime}$ and $\mathbf{1 3 b}, \mathbf{b}^{\prime}$ were readily separated, on a gram scale, by flash chromatography on silica gel, using a ternary mixture of toluene/nheptane/THF $(70: 30: 0$ to $70: 30: 1.5)$. The enantiopure acids $(+)-\mathbf{1 0 a}$ and $(+)-\mathbf{1 0 b}$ have been obtained by removal of the 1-phenyl-2-cyanoethyl chain by treatment with DBU, purification of the salt by flash chromatography and treatment with concentrated hydrochloric acid.

In additional experiments, in order to expand the family of planar chiral acids, we have converted the enantiopure phosphoric acid (+)-10a, into the corresponding $N$-triflyl phosphoramide ${ }^{[25]} \quad(+)-\mathbf{1 6 a}$ (Scheme 4). For this purpose, we have reacted at first $(+)-\mathbf{1 0}$ a with the Vilsmeyer reagent, (chloromethy- 


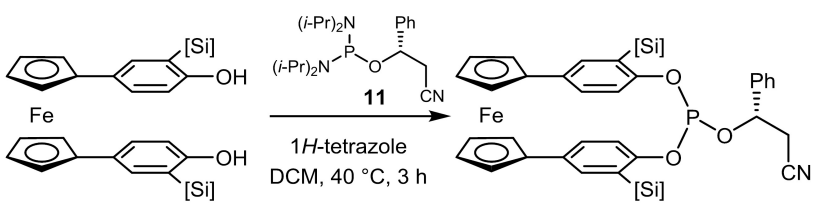

$[\mathrm{Si}]=\mathrm{SiPh}_{3}, \quad \mathbf{6 a}$

$[\mathrm{Si}]=\mathrm{Si}^{\mathrm{t}} \mathrm{BuPh}_{2}, \mathbf{6 b}$

$[\mathrm{Si}]=\mathrm{SiPh}_{3}, \quad \mathbf{1 2 a}+\mathbf{1 2} \mathbf{a}^{\prime}, 37 \%, 6: 4$ $[\mathrm{Si}]=\mathrm{Si}^{\mathrm{t}} \mathrm{BuPh}_{2}, \mathbf{1 2 b}+\mathbf{b} \mathbf{2} \mathbf{b}^{\prime}, 36 \%, 6: 4$ TBHP, DCM, $0{ }^{\circ} \mathrm{C}, 15 \mathrm{~min}$
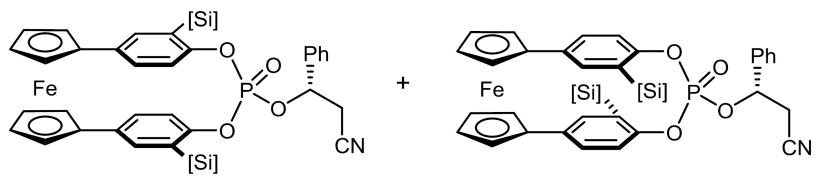

$[\mathrm{Si}]=\mathrm{SiPh}_{3}, \quad 13 \mathrm{a}, 63 \%[\alpha]_{\mathrm{D}}^{20}=+653$ $[\mathrm{Si}]=\mathrm{Si}^{\mathrm{t}} \mathrm{BuPh}_{2}, \mathbf{1 3 \mathbf { b }}, 62 \%[\alpha]_{\mathrm{D}}^{20}=+155$

$[\mathrm{Si}]=\mathrm{SiPh}_{3}, \quad 13 \mathrm{a}, 36 \%[\alpha]_{D}^{20}=-608$ $[\mathrm{Si}]=\mathrm{Si}^{t} \mathrm{BuPh}_{2}, 13 \mathbf{b}^{\prime}, 38 \%[\alpha]_{\mathrm{D}}^{20}=-484$

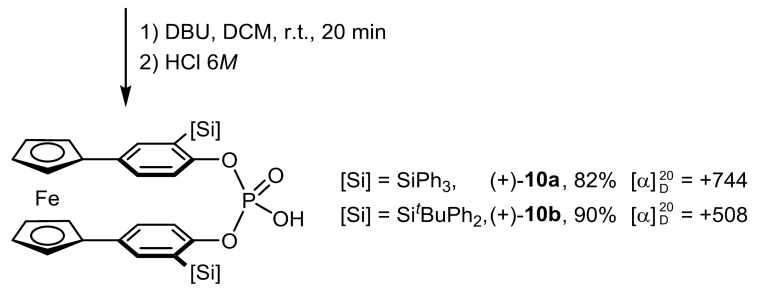

Scheme 3. Synthesis of the phosphoric acids $(+)-\left(R_{\mathrm{P}}\right)-\mathbf{1 0}$ a and $(+)-\mathbf{1 0 b}$ using the chiral phosphorylating agent $(S)-\mathbf{1 1}$. The diastereomeric mixtures $\mathbf{1 3}$ have been separated by flash chromatography on silica gel.

lene)dimethylammonium chloride, generated in situ from oxalyl chloride and $\mathrm{DMF},{ }^{[26]}$ to obtain the corresponding phosphorochloridate $(+)-\mathbf{1 4 a}$. Attempts to introduce the $N$-triflyl phosphoramide function directly from phosphorochloridate $(+)-\mathbf{1 4 a}$ with trifluoromethanesulfonamide, in standard conditions ${ }^{[20 \mathrm{~b}, 25]}$ or in basic media ${ }^{[27]}$ failed. Thus, we considered then a two-step procedure: we reacted $(+)-14$ a with a large excess of liquid ammonia, ${ }^{[28]}$ which delivered the phosphoramidate $(+)-\mathbf{1 5} \mathbf{a}$ in high yield $(86 \%)$. The trifluoromethylsulfonyl moiety was introduced then using $N$-phenyltriflimide in basic media $(\mathrm{NaH})$. The desired enantiopure $N$-triflylphosphoramide $(+)-\mathbf{1 6}$ a was isolated in $77 \%$ yield.

Recrystallization of the solid phosphorochloridate $(+)-\mathbf{1 4}$ a from slow evaporation of its solution in an $n$ heptane/EtOAc mixture yielded single crystals suitable for X-ray crystallography (Figure 4). The crystallographic analysis showing an $\left(R_{\mathrm{P}}\right)$ configuration for $(+)-14 \mathbf{a},{ }^{[22]}$ these data confirmed the previous stereochemical assignment for $\left(R_{\mathrm{P}}\right)-(+)-\mathbf{1 0}$ a.

With the new acids $\mathbf{1 0}$ and $\mathbf{1 6}$ in hand, we turned our attention to their application in organocatalyzed asymmetric aza-Friedel-Crafts reactions.

The enantioselective Friedel-Crafts alkylation reaction represents one of the most powerful methods for the synthesis of structurally diverse enantioenriched

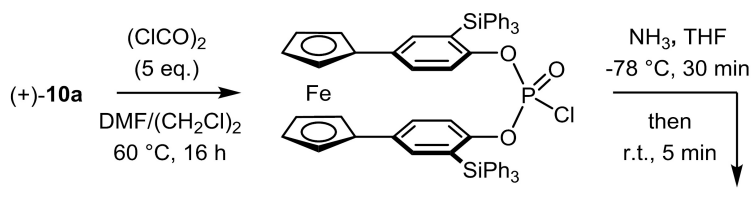

$(+)-14 a, 37 \%$

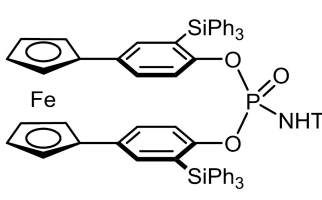

(+)-16a, $77 \%$

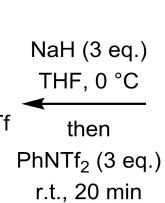

r.t., $20 \mathrm{~min}$

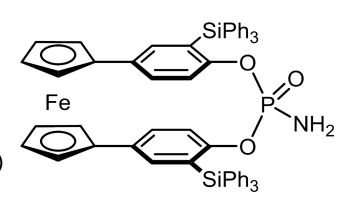

$(+)-15 a, 86 \%$
Scheme 4. Synthesis of the planar chiral $N$-triflyl phosphoramide (+)-16a.

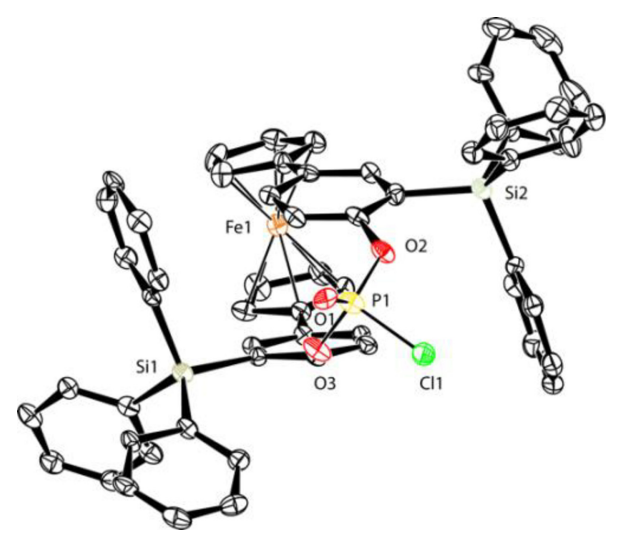

Figure 4. ORTEP drawing of phosphorochloridate $(+)-\mathbf{1 4 a}$.

aromatic and heteroaromatic compounds with a benzylic carbon stereocenter. ${ }^{[2]}$ After the work carried out on metal-catalyzed asymmetric Friedel-Crafts reactions, ${ }^{[30]}$ the last decade has witnessed considerable progress in the development of organocatalyzed asymmetric variants. ${ }^{[31]}$ These reactions are particularly attractive since they do not require strictly anhydrous conditions or inert atmosphere. Research efforts have been devoted notably to chiral Brønsted acids promoted Friedel-Crafts reactions on indole substrates. ${ }^{[32]}$ In this context, we focused our studies on the catalytic additions of the indole derivatives $\mathbf{1 7}$ to $N$-tosylaldimines, $\mathbf{1 8}$, which provide 3 -indolyl-methanamines, 19. ${ }^{[33]}$ The resulting 3-indolyl-methanamine structural motif represents a highly relevant synthetic target, as far as it can be found in a variety of biologically active, natural ${ }^{[34]}$ or synthetic products. ${ }^{[35]}$

We started our study with the reaction of indole $17 \mathbf{a}$ and $N$-tosylbenzaldimine $18 \mathbf{a}$ in toluene, with (+)-10 a as the catalyst (Table 1). At r.t., an enantiomeric excess of only $41 \%$ was obtained. However, lowering of the reaction temperature resulted in an increase of the enantioselectivity with a maximum $83 \%$ ee at $-40{ }^{\circ} \mathrm{C}$ (entries 2, 3). Further decrease of 
Table 1. Screening of catalysts and reaction conditions for the aza-Friedel-Crafts reaction between indole and $N$ tosylbenzaldimine. ${ }^{[a]}$

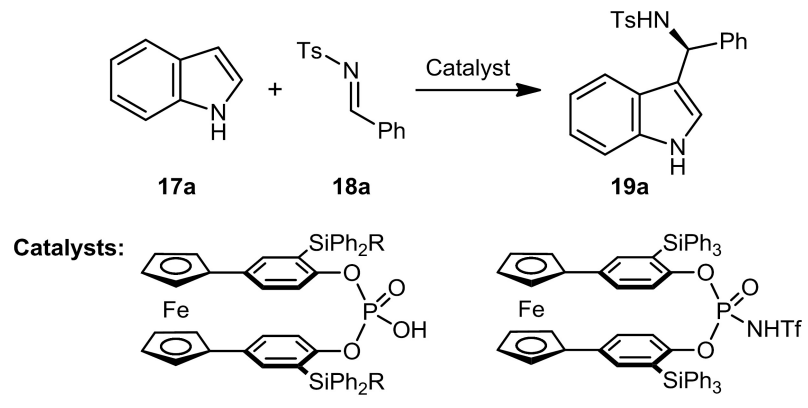

$(+)-10 a \quad R=P h$

$(+)-10 \mathrm{~b} \quad \mathrm{R}={ }^{t} \mathrm{Bu}$

$(+)-16 a$

\begin{tabular}{|c|c|c|c|c|c|c|}
\hline Entry & Cat. & Solvent & $\begin{array}{l}\mathrm{T} \\
{\left[{ }^{\circ} \mathrm{C}\right]}\end{array}$ & $\begin{array}{l}\text { Time } \\
{[\mathrm{h}]}\end{array}$ & $\begin{array}{l}\text { Yield } \\
{[\%]^{[b]}}\end{array}$ & $\begin{array}{l}\text { e.e. }[\%]^{[c]} \\
\text { (config.) }\end{array}$ \\
\hline 1 & $(+) \mathbf{- 1 0} \mathbf{a}$ & toluene & r.t. & 2 & 80 & $41(S)$ \\
\hline 2 & $(+)-10 \mathbf{a}$ & toluene & -20 & 20 & 97 & $62(S)$ \\
\hline 3 & $(+)-\mathbf{1 0} \mathbf{a}$ & toluene & -40 & 36 & $>99$ & $83(S)$ \\
\hline 4 & $(+)-\mathbf{1 0} \mathbf{a}$ & toluene & -60 & 36 & 67 & $77(S)$ \\
\hline 5 & $(+)-10 \mathbf{a}$ & toluene & -78 & 72 & 37 & $23(S)$ \\
\hline 6 & $(+)-\mathbf{1 0 b}$ & toluene & r.t. & 6 & 75 & $31(S)$ \\
\hline 7 & $(+)-\mathbf{1 0 b}$ & toluene & -40 & 36 & 58 & $48(S)$ \\
\hline 8 & $(+)-\mathbf{1 6} \mathbf{a}$ & toluene & -40 & 36 & 88 & $64(S)$ \\
\hline 9 & $(+)-\mathbf{1 0} \mathbf{a}$ & $\mathrm{Et}_{2} \mathrm{O}$ & -40 & 36 & 10 & n.d. \\
\hline 10 & $(+)-10 \mathbf{a}$ & $\mathrm{CH}_{2} \mathrm{Cl}_{2}$ & -40 & 36 & 32 & $16(S)$ \\
\hline 11 & $(+)-\mathbf{1 0 a}$ & $\mathrm{C}_{6} \mathrm{H}_{5} \mathrm{Cl}$ & -40 & 36 & 55 & $64(S)$ \\
\hline 12 & $(+)-\mathbf{1 0} \mathbf{a}$ & mesitylene & -40 & 36 & 92 & $96(S)$ \\
\hline 13 & $(+)-\mathbf{1 0 b}$ & mesitylene & -40 & 36 & 26 & $43(S)$ \\
\hline
\end{tabular}

${ }^{[a]}$ Reactions were carried out with $0.1 \mathrm{mmol}$ of $\mathbf{1 8 a}, 0.15 \mathrm{mmol}$ of $\mathbf{1 7 a}$ and $10 \mathrm{~mol} \%$ of catalyst in $1 \mathrm{~mL}$ of toluene. ${ }^{[\mathrm{b}]}$ Yield of isolated product. ${ }^{[c]}$ Determined by HPLC analysis on a chiral stationary phase. Configuration assigned from the $[\alpha]_{\mathrm{D}}$ value. ${ }^{[9 a, 39]}$

the temperature led to significant drop of both the chemical yields and enantiomeric excesses (entries 4, $5)$.

The same beneficial effect of lowering the reaction temperature was observed for catalyst $(+)-\mathbf{1 0 b}$, with an increase of the ee going from r.t. to $-40^{\circ} \mathrm{C}(31 \%$ and $48 \%$ ee respectively, entries 6, 7). Catalyst $(+)-\mathbf{1 0 b}$ is however less efficient than $(+)-\mathbf{1 0} \mathbf{a}$ in terms of both catalytic activity and enantioselectivity. Also, the $N$-triflyl phosphoramide $(+)-\mathbf{1 6 a})^{[36]}$ gave lower enantiomeric excess than the corresponding phosphoric acid (+)-10a (entry 8 vs. 3 ).

In additional experiments, we have performed the above aza-Friedel-Crafts reaction in toluene at different concentrations $(0.05,0.1$ and $0.5 M)$ and have identified $0.1 M$ as the optimal concentration. Finally, we have evaluated the influence of molecular sieves, since Akiyama $^{[37]}$ and You $^{[38]}$ have observed its beneficial effects in enantioslective Friedel-Crafts reactions. However, with our catalysts, we did not observe any improvement.

The influence of the solvent on the conversion rates and enantioselectivity levels was also examined (entries 9-13). A quick screening established that, with $10 \mathrm{~mol} \%$ of $(+)-\mathbf{1 0 a}$ as the catalyst, diethyl ether and chlorinated solvents have deleterious effects (entries 9-11), while the use of mesitylene, instead of toluene, improved the enantioselectivity to $96 \%$ ee (entry 12). In mesitylene, catalyst (+)-10b gave only moderate catalytic activity and a $43 \%$ enantiomeric excess (entry 13).

With (+)-10a, attempts to reduce the catalyst loading to $2 \mathrm{~mol} \%$ gave poor results, with a conversion rate of only $24 \%$ after $36 \mathrm{~h}$ at $-40^{\circ} \mathrm{C}$. So, finally, the optimized conditions involve the use of catalyst $(+)-10 a$, which displays bulky triphenylsilyl substituents, at a $10 \mathrm{~mol} \%$ catalyst loading, in mesitylene at $-40^{\circ} \mathrm{C}$. Under such conditions the desired addition product 19a is obtained in $92 \%$ yield and an excellent level of enantioselectivity ( $96 \%$ ee).

The high efficiency of catalyst $(+)-\mathbf{1 0 a}$ led us to investigate the substrate scope of this enantioselective aza-Friedel-Crafts reaction, by varying the substitution patterns of both indoles $\mathbf{1 7}$ and $\mathrm{N}$-tosylbenzaldimines 18. The results of these studies are summarized in Table 2. 
Table 2. Additional examples of aza-Friedel-Crafts reactions promoted by $(+)-\mathbf{1 0} \mathbf{a}^{[\mathrm{a}]}$

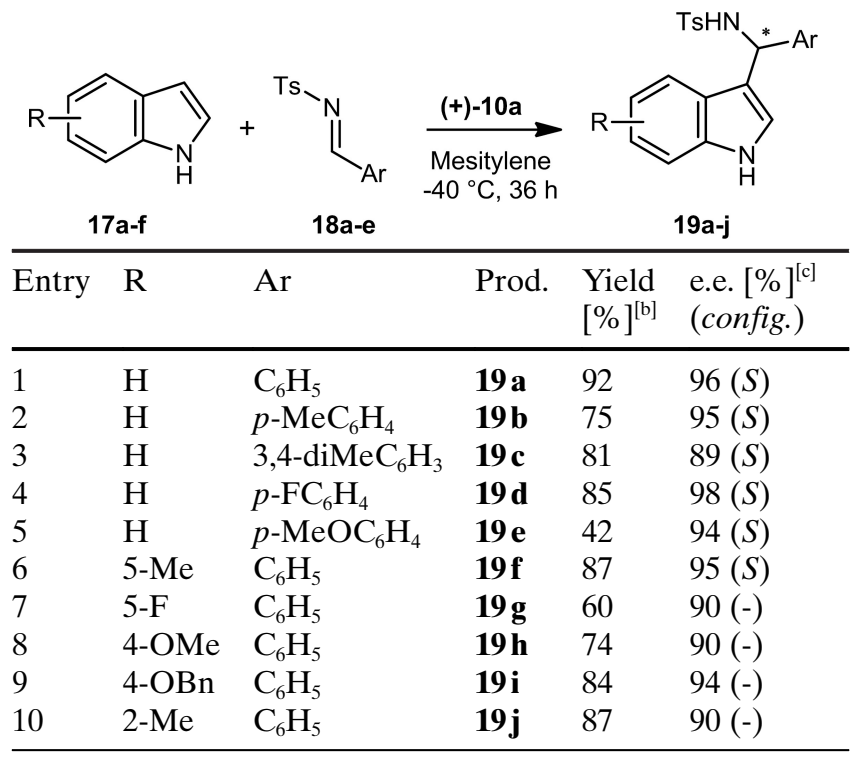

[a] Reactions were carried out with $0.05 \mathrm{mmol}$ of $\mathbf{1 8}$, $0.075 \mathrm{mmol}$ of $\mathbf{1 7}$ and $10 \mathrm{~mol} \%$ of catalyst in $0.5 \mathrm{~mL}$ of mesitylene. ${ }^{[b]}$ Yield of isolated product. ${ }^{[c]}$ Determined by HPLC analysis on a chiral stationary phase.

The reactions of indole $\mathbf{1 7 a}$ with tolyl and xylylaldimines $(\mathbf{1 8 b}, \mathbf{c})$, as well as with fluorobenzaldimine (18d) afforded good yields and high enantioselectivity $(89-98 \%$ ee). The 4-methoxy substituted benzaldimine $18 \mathrm{e}$ led to the addition product $19 \mathrm{e}$ with a significantly lower yield (entry 5, 42\%), but gratifyingly, the high level of enantioselectivity was preserved $(94 \%$ ee).

The methyl substituted indoles $\mathbf{1 7} \mathbf{b , f}$, including the sterically hindered and less reactive 2-methyl-substituted derivative $\mathbf{1 7 f}$, led to the desired addition products 19f,j in good yields and enantiomeric excess (entries 6,10). Indoles $\mathbf{1 7} \mathbf{c}-\mathbf{e}$ bearing either fluorine or alkoxy groups led to slightly decreased yields of isolated products 19 $\mathbf{g - i}$ (entries 7-9, 60-84\% yields), however the same high levels of enantioselectivity were obtained (90-94\% ee).

The few examples above demonstrate the efficiency of the new catalyst $\mathbf{1 0 a}$ in a range of reactions between arylimines and $1 H$-indoles. The attempted reaction of 1 -methylindole with $N$-tosylbenzaldimine $18 \mathbf{a}$, under the same reaction conditions, failed. This result suggests that $\mathbf{1 0}$ a might act as a bifunctional catalyst which activates simultaneously the imine and the indole substrates, by means of its acidic $\mathrm{POH}$ and basic $\mathrm{P}(\mathrm{O})$ functions respectively, as shown in Figure 5. An analogous activation mode has been postulated by Goodman ${ }^{[40]}$ for aza-Friedel-Crafts reactions between indole and $N$-tosylimines promoted by BINOL-phosphoric acid derivatives.

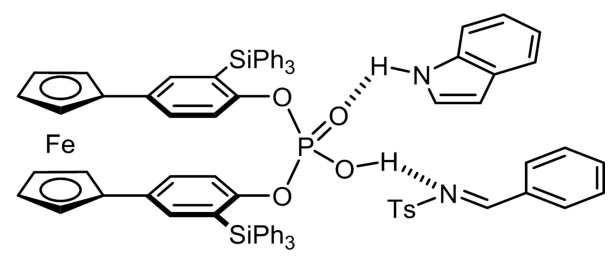

Figure 5. Postulated activation mode in aza-Friedel-Crafts reactions.

In summary, we have described here a suitable procedure for the synthesis of phosphoric acids based on a planar chiral paracyclophane scaffold which displays silyl substituents on its arylidene moieties. The silyl substituents are introduced on the aryl units by retro-Brook type rearrangements. These acids have been obtained easily in enantiomerically pure form, by taking advantage of the chiral (S)-(1-phenyl-2cyanoethyl)phosphorodiamidite to introduce the phosphorus function. The new acids proved to be excellent catalysts for aza-Friedel-Crafts reactions on indoles, giving good catalytic activity and enantiomeric excesses up to $98 \%$. These studies expand the family of planar chiral phosphoric acids previously introduced by our group ${ }^{[13]}$ and confirm their good potential for uses in asymmetric organocatalysis.

\section{Experimental Section}

\section{Representative Procedure for the Enantioselective aza-Friedel-Crafts Reactions.}

A solution of $N$-sulfonylimine $\mathbf{1 8 a}(26 \mathrm{mg}, 0.10 \mathrm{mmol}$, 1 equiv.) and phosphoric acid (+)-10a $(9.5 \mathrm{mg}, 0.01 \mathrm{mmol}$, $10 \mathrm{~mol} \%)$ in mesitylene $(1 \mathrm{~mL})$ was cooled to $-40^{\circ} \mathrm{C}$. Then indole 17a (17 mg, $0.15 \mathrm{mmol}, 1.5$ equiv.) was added in one portion at $-40^{\circ} \mathrm{C}$ and the mixture was stirred for $36 \mathrm{~h}$. Then the mixture was quenched by addition of a saturated aqueous solution of $\mathrm{NaHCO}_{3}(3 \mathrm{~mL})$. The mixture was extracted with EtOAc $(10 \mathrm{~mL})$. The organic layer was washed with water $(5 \mathrm{~mL})$ and brine $(5 \mathrm{~mL})$, separated, and dried over anhydrous $\mathrm{Na}_{2} \mathrm{SO}_{4}$. The solvents were removed under reduced pressure and the residue was purified by flash chromatography (eluent: $n$-heptane/EtOAc 2:8) to afford the indol-3yl-methanamine 19a $\quad(35 \mathrm{mg}, \quad 92 \%$ yield $) ;{ }^{1} \mathrm{H} \quad \mathrm{NMR}$ $\left(300 \mathrm{MHz}, \mathrm{CDCl}_{3}\right): \delta=8.01(\mathrm{bs}, 1 \mathrm{H}), 7.57(\mathrm{~d}, J=8.3 \mathrm{~Hz}, 2 \mathrm{H})$, $7.31(\mathrm{~d}, J=8.3 \mathrm{~Hz}, 2 \mathrm{H}), 7.25-7.14(\mathrm{~m}, 7 \mathrm{H}), 7.11(\mathrm{~d}, J=8.3 \mathrm{~Hz}$, 2H), $7.00(\mathrm{dd}, J=8.3,7.1 \mathrm{~Hz}, 1 \mathrm{H}), 6.68(\mathrm{bd}, J=2.6 \mathrm{~Hz}, 1 \mathrm{H})$, $5.85(\mathrm{bd}, J=6.8 \mathrm{~Hz}, 1 \mathrm{H}), 2.37(\mathrm{~s}, 3 \mathrm{H}) ;{ }^{13} \mathrm{C} \mathrm{NMR}(75 \mathrm{MHz}$, $\left.\mathrm{CDCl}_{3}\right): \delta=143.2,140.4,137.6,136.7,129.4,128.5,127.5$, 127.3, 125.5, 123.9, 122.7, 120.1, 119.4, 116.5, 111.4, 55.2, 21.6. The $e e$ were determined by HPLC using a CHIRALPAK ${ }^{\circledR}$ ID column, $30^{\circ} \mathrm{C}$, eluent: $i-\mathrm{PrOH} / n$-hexane $30: 70$, $0.9 \mathrm{~mL} \cdot \mathrm{min}^{-1}$ [detection at $254 \mathrm{~nm}$ ]: retention times $13.3 \mathrm{~min}$ for $(S)$-19a (major) and $16.6 \mathrm{~min}$ for $(R)-19 a$ (minor); $[\alpha]_{\mathrm{D}}^{20}:-21.6\left(c=1, \mathrm{CHCl}_{3}, 96 \% e e\right)$. 


\section{Acknowledgements}

Authors thank the ANR funding agency for financial support to the CHIRACID project (ANR Blanc SIMI 7, 2011-2015), the COST action 'Organocatalysis' (ORCA, CM0905) and the Ecole Doctorale 470, Paris-Sud University for Ph. D. grant to J.S.

\section{References}

[1] a) P. I. Dalko, L. Moisan, Angew. Chem. Int. Ed. 2001, 40, 3726-3748; b) J. Seayad, B. List, Org. Biomol. Chem. 2005, 3, 719-724.

[2] a) M. Rueping, A. Kuenkel, I. Atodiresei, Chem. Soc. Rev. 2011, 40, 4539-4549; b) T. Akiyama, K. Mori, Chem. Rev. 2015, 115, 9277-9306.

[3] T. Akiyama, J. Itoh, K. Yokota, K. Fuchibe, Angew. Chem. Int. Ed. 2004, 43, 1566-1568.

[4] D. Uraguchi, M. Terada, J. Am. Chem. Soc. 2004, 126, 5356-5357.

[5] A. Zamfir, S. Schenker, M. Freund, S. B. Tsogoeva, Org. Biomol. Chem. 2010, 8, 5262-5276.

[6] a) G. B. Rowland, H. Zhang, E. B. Rowland, S. Chennamadhavuni, Y. Wang, J. C. Antilla, J. Am. Chem. Soc. 2005, 127, 15696-15697; b) A. A. Desai, L. Huang, W. D. Wulff, G. B. Rowland, J. C. Antilla, Synthesis 2010, 2106-2109.

[7] a) E. B. Rowland, G. B. Rowland, E. Rivera-Otero, J. C. Antilla, J. Am. Chem. Soc. 2007, 129, 12084-12085; b) A. A. Desai, W. D. Wulff, Synthesis 2010, 3670-3680.

[8] a) E. G. Gutierrez, E. J. Moorhead, E. H. Smith, V. Lin, L. K. G. Ackerman, C. E. Knezevic, V. Sun, S. Grant, A. G. Wenzel, Eur. J. Org. Chem. 2010, 3027-3031; b) K. Mori, K. Ehara, K. Kurihara, T. Akiyama, J. Am. Chem. Soc. 2011, 133, 6166-6169.

[9] a) F.-X. Xu, D. Huang, C. Han, W. Shen, X.-F. Lin, Y.G. Wang, J. Org. Chem. 2010, 75, 8677-8680; b) I. Corić, S. Müller, B. List, J. Am. Chem. Soc. 2010, 132, 17370 17373; c) C.-H. Xing, Y.-X. Liao, J. Ng, Q.-S. Hu, J. Org. Chem. 2011, 76, 4125-4131.

[10] Q.-S. Guo, D.-M. Du, J. Xu, Angew. Chem. Int. Ed. 2008, 47, 759-762.

[11] T. Akiyama, Y. Saitoh, H. Morita, K. Fuchibe, $A d v$. Synth. Catal. 2005, 347, 1523-1526.

[12] D. Enders, M. Ludwig, G. Raabe, Chirality 2012, 24, 215-222.

[13] a) J. Stemper, K. Isaac, V. Duret, P. Retailleau, A Voituriez, J.-F. Betzer, A. Marinetti, Chem. Commun. 2013, 49, 6084-6086; b) J. Stemper, K. Isaac, J. Pastor, G. Frison, P. Retailleau, A. Voituriez, J.-F. Betzer, A. Marinetti, Adv. Synth. Catal. 2013, 355, 3613-3624.

[14] K. Isaac, J. Stemper, V. Servajean, P. Retailleau, J. Pastor, G. Frison, K. Kaupmees, I. Leito, J.-F. Betzer, A. Marinetti, J. Org. Chem. 2014, 79, 9639-9646.

[15] R. I. Storer, D. E. Carrera, Y. Ni, D. W. C. MacMillan, J. Am. Chem. Soc. 2006, 128, 84-86.

[16] a) G. B. Rowland, E. B. Rowland, Y. Liang, J. A. Perman, J. C. Antilla, Org. Lett. 2007, 9, 2609-2611; b) M. J. Wanner, P. Hauwert, H. E. Schoemaker, R. de Gelder, J. H. van Maarseveen, H. Hiemstra, Eur. J. Org. Chem.
2008, 180-185; c) Q. Kang, X.-J. Zheng, S.-L. You, Chem. Eur. J. 2008, 14, 3539-3542.

[17] a) H. Kitajima, K. Ito, Y. Aoki, T. Katsuki, Bull. Chem. Soc. Jpn. 1997, 70, 207-217; b) V. K. Aggarwal, M. P. Coogan, R. A. Stenson, R. V. H. Jones, R. Fieldhouse, J. Blacker, Eur. J. Org. Chem. 2002, 319-326; c) R. R. Milburn, S. M. S. Hussain, O. Prien, Z. Ahmed, V. Snieckus, Org. Lett. 2007, 9, 4403-4406; d) Q. Wang, X. Chen, L. Tao, L. Wang, D. Xiao, X.-Q. Yu, L. Pu, J. Org. Chem. 2007, 72, 97-101.

[18] R. Kuwano, T. Uemura, M. Saitoh, Y. Ito, Tetrahedron Lett. 1999, 40, 1327-1330.

[19] a) A. G. Brook, J. D. Pascoe, J. Am. Chem. Soc. 1971, 93, 6224-6227; b) A. G. Brook, Acc. Chem. Res. 1974, 7, 77-84; c) K. Tomooka, Vol. 2 (Ed.: Z. R. I. Marek), Wiley, Chichester, 2004, pp. 749-828.

[20] a) K. Maruoka, T. Itoh, Y. Araki, T. Shirasaka, H. Yamamoto, Bull. Chem. Soc. Jpn. 1988, 61, 2975-2976; b) M. Rueping, B. J. Nachtsheim, R. M. Koenigs, W. Ieawsuwan, Chem. Eur. J. 2010, 16, 13116-13126.

[21] a) J. Nielsen, M. Taagaard, J. E. Marugg, J. H. van Boom, O. Dahl, Nucleic Acids Res. 1986, 14, 7391-7403; b) W. Bannwarth, A. Trzeciak, Helv. Chim. Acta 1987, 70, 175-186; c) R. Gukathasan, M. Massoudipour, I. Gupta, A. Chowdhury, S. Pulst, S. Ratnam, Y. S. Sanghvi, S. A. Laneman, J. Organomet. Chem. 2005, 690, 2603-2607.

[22] CCDC 1492132 for $[(+)-(\mathbf{1 0 a})]_{2} \mathrm{Ca}$ and CCDC 1492133 for (+)-(14a) contain the supplementary crystallographic data for this paper. These data can be obtained free of charge from The Cambridge Crystallographic Data Centre via URL www.ccdc.cam.ac.uk/data_request/cif.

[23] M. Hatano, K. Moriyama, T. Maki, K. Ishihara, Angew. Chem. Int. Ed. 2010, 49, 3823-3826.

[24] K. Isaac, J. Stemper, P. Retailleau, J.-F. Betzer, A. Marinetti, Eur. J. Org. Chem. 2014, 4099-4106.

[25] BINOL-derived $N$-triflyl phosphoramides were introduced in 2006 by Yamamoto: D. Nakashima, H. Yamamoto, J. Am. Chem. Soc. 2006, 128, 9626-9627.

[26] P. M. Cullis, J. Fawcett, G. A. Griffith, M. J. P. Harger, M. Lee, J. Am. Chem. Soc. 2001, 123, 4147-4154.

[27] A. Borovika, P. Nagorny, Tetrahedron 2013, 69, 57195725 .

[28] a) F. R. Atherton, H. T. Openshaw, A. R. Todd, J. Chem. Soc. 1945, 382-385; b) I. Čorić, B. List, Nature 2012, 483, 315-319.

[29] M. Bandini, A. Melloni, A. Umani-Ronchi, Angew. Chem. Int. Ed. 2004, 43, 550-556.

[30] T. B. Poulsen, K. A. Jørgensen, Chem. Rev. 2008, 108, 2903-2915.

[31] a) S.-L. You, Q. Cai, M. Zeng, Chem. Soc. Rev. 2009, 38, 2190-2201; b) V. Terrasson, R. Marcia de Figueiredo, J.M. Campagne, Eur. J. Org. Chem. 2010, 2635-2655.

[32] a) M. Zeng, S.-L. You, Synlett 2010, 1289-1301; b) G. Bartoli, G. Bencivenni, R. Dalpozzo, Chem. Soc. Rev. 2010, 39, 4449-4465; c) R. Dalpozzo, Chem. Soc. Rev. 2015, 44, 742-778; d) H. Wu, Y.-P. He, F. Shi, Synthesis 2015, 47, 1990-2016.

[33] Q. Kang, Z.-A. Zhao, S.-L. You, J. Am. Chem. Soc. 2007, 129, 1484-1485. 
[34] a) B. Bao, Q. Sun, X. Yao, J. Hong, C.-O. Lee, C. J. Sim, K. S. Im, J. H. Jung, J. Nat. Prod. 2005, 68, 711-715; b) B. Bao, Q. Sun, X. Yao, J. Hong, C.-O. Lee, H. Y. Cho, J. H. Jung, J. Nat. Prod. 2007, 70, 2-8; c) K.-D. Feussner, K. Ragini, R. Kumar, K. M. Soapi, W. G. Aalbersberg, M. K. Harper, B. Carte, C. M. Ireland, Nat. Prod. Rep. 2012, 29, 1424-1462.

[35] a) K. Ewan, B. Pajak, M. Stubbs, H. Todd, O. Barbeau, C. Quevedo, H. Botfield, R. Young, R. Ruddle, L. Samuel, A. Battersby, F. Raynaud, N. Allen, S. Wilson, B. Latinkic, P. Workman, E. McDonald, J. Blagg, W. Aherne, T. Dale, Cancer Res. 2010, 70, 5963-5973; b) S. Tyagarajan, P. K. Chakravarty, M. Park, B. Zhou, J. B. Herrington, K. Ratliff, R. M. Bugianesi, B. Williams, R. J. Haedo, A. M. Swensen, V. A. Warren, M. Smith, M. Garcia, G. J. Kaczorowski, O. B. McManus, K. A. Lyons, X. Li, M. Madeira, B. Karanam, M. Green, M. J. Forrest, C. Abbadie, E. McGowan, S. Mistry, N. Jochnowitz, J. L. Duffy, Bioorg. Med. Chem. Lett. 2011, 21, 869-873; c) V. K. Rao, B. S. Chhikara, A. N. Shirazi, R. Tiwari, K. Parang, A. Kumar, Bioorg. Med. Chem. Lett. 2011, 21, 3511-3514; d) P. Nandhikonda, W. Z. Lynt, M. M. McCallum, T. Ara, A. M. Baranowski, N. Y. Yuan, D. Pearson, D. D. Bikle, R. K. Guy, L. A.
Arnold, J. Med. Chem. 2012, 55, 4640-4651; e) P. S. Sidhu, N. Nassif, M. M. McCallum, K. Teske, B. Feleke, N. Y. Yuan, P. Nandhikonda, J. M. Cook, R. K. Singh, D. D. Bikle, L. A. Arnold, ACS Med. Chem. Lett. 2014, 5, 199-204; f) P. S. Sidhu, K. Teske, B. Feleke, N. Y. Yuan, M. L. Guthrie, G. B. Fernstrum, N. D. Vyas, L. Han, J. Preston, J. W. Bogart, N. R. Silvaggi, J. M. Cook, R. K. Singh, D. D. Bikle, L. A. Arnold, Cancer Chemoth. Pharm. 2014, 74, 787-798.

[36] D. Enders, A. A. Narine, F. Toulgoat, T. Bisschops, Angew. Chem. Int. Ed. 2008, 47, 5661-5665.

[37] J. Itoh, K. Fuchibe, T. Akiyama, Angew. Chem. Int. Ed. 2008, 47, 4016-4018.

[38] a) Y.-F. Sheng, G.-Q. Li, Q. Kang, A.-J. Zhang, S.-L. You, Chem. Eur. J. 2009, 15, 3351-3354; b) F.-L. Sun, M. Zeng, Q. Gu, S.-L. You, Chem. Eur. J. 2009, 15, 87098712.

[39] a) Y.-X. Jia, J.-H. Xie, H.-F. Duan, L.-X. Wang, Q.-L. Zhou, Org. Lett. 2006, 8, 1621-1624; b) Y.-Q. Wang, J. Song, R. Hong, H. Li, L. Deng, J. Am. Chem. Soc. 2006, 128, 8156-8157; c) G.-X. Li, J. Qu, Chem. Commun. 2012, 48, 5518-5520.

[40] L. Simón, J. M. Goodman, J. Org. Chem. 2010, 75, 589597. 


\section{UPDATES}

Silyl-Substituted Planar Chiral Phosphoric Acids with

Ferrocene-bridged Paracyclophane Frameworks:

Synthesis, Characterization, and Uses in Enantioselective aza-Friedel-Crafts Reactions

Adv. Synth. Catal. 2016, 358, 1-9

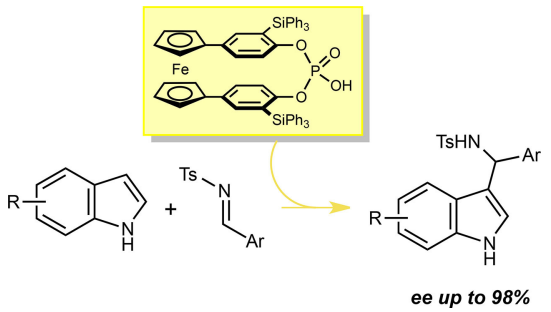

J. Stemper, K. Isaac, N. Ghosh, H. Lauwick, G. Le Duc,

P. Retailleau, A. Voituriez, J.-F. Betzer*, A. Marinetti* 